\title{
Synthesis of SMC algorithms applied to wind generator
}

\author{
Houaria Abdelli ${ }^{1}$, Abdelkader Mezouar ${ }^{2}$, Mokhtar Bendjebbar ${ }^{3}$, Kheira Belgacem ${ }^{4}$ \\ ${ }^{1,3}$ Diagnostic group LDEE, University of Science and Technology Mohamed Boudiaf, Oran, Algeria \\ ${ }^{2,4}$ Laboratory of Electrical Engineering, Taher Moulay University, Saida, Algeria
}

\begin{tabular}{l}
\hline \hline Article Info \\
\hline Article history: \\
Received May 26, 2020 \\
Revised Jan 27, 2021 \\
Accepted Feb 3, 2021 \\
\hline
\end{tabular}

\begin{abstract}
The use of the classical (SMC) applied to control of stator's powers of DFIG, gives the problem of chattering, therefore to avoid this phenomenon a robust algorithm (STSMC) is applied. This paper presents a comparison of conventional SMC with the proposed strategy of STSMC algorithm. The results are obtained using MATLAB and demonstrate stability and robustness of this algorithm.
\end{abstract}

Keywords:

DFI generator

Power control

SMC algorithms

Synthesis

Wind

This is an open access article under the CC BY-SA license.

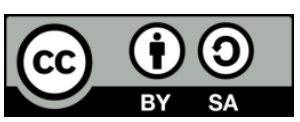

\section{Corresponding Author:}

Abdelli Houaria

Department of Electrical Engineering,

University of Science and technology Mohamed Boudiaf

USTO (31000) Oran, Algeria.

Email: abdelli_houaria@yahoo.com

\section{INTRODUCTION}

Energy consumption has increased over the last decades considerably due to massive industrialization. A good alternative is to use renewable energies, which offer the possibility of producing electricity properly [1]. Among the renewable energies we find the wind turbine, which is becoming competitive in terms of production costs. It is reducing the emissions of greenhouse gases. Today, variable speed wind turbines based on (DFIG) offers many benefits, such as their efficient power density, the dimensioning of the converter on the rotor side is reduced to $30 \%$ of the nominal power of the machine [2], [3]. To have maximum wind power we use variable speed wind turbines [4], so to achieve this goal, the peak turbine speed ratio must be maintained at its optimum value despite the variation in wind speed [5], [6]. To solve the problem of tracking the maximum power point, different control techniques have been used, among them conventional (SMC). This controller offers some advantages: relative simplicity of implementation, robustness and external disturbances [7].

SMC is a robust control method [8], which guarantees the performance of the dynamic system by rejecting any disturbance acting on it. Despite the simplicity of its conception, the discontinuity of this command gives rise to the phenomenon of chattering. Several researchers have proposed solutions to avoid this phenomenon and guaranteed stability in steady state. [9], [10].

This paper presents a robust super-twisting sliding mode control of doubly fed induction generator (DFIG) based wind turbines. The simulation results showed a good STSMC control compared to the SMC algorithm. The rest of this article is organized as follows: Section 2 presents the wind turbine and DFIG modeling. The Section 3 describes the fundamental formulation of the proposed STSMC applied to the power 
based on DFIG. Section 4 presents the simulation results to demonstrate the performance of the proposed control scheme. At the end, conclusion is given in Section 5.

\section{MATERIAL AND METHOD}

\subsection{The generator mode1}

Block diagram of a wind turbine based on DFIG is given in figure 1. The model contains of a wind turbine, DFIG, converters, and a gearbox. The stator is connected to the network via a three-phase transformer and the rotor via another three-phase current source [11].

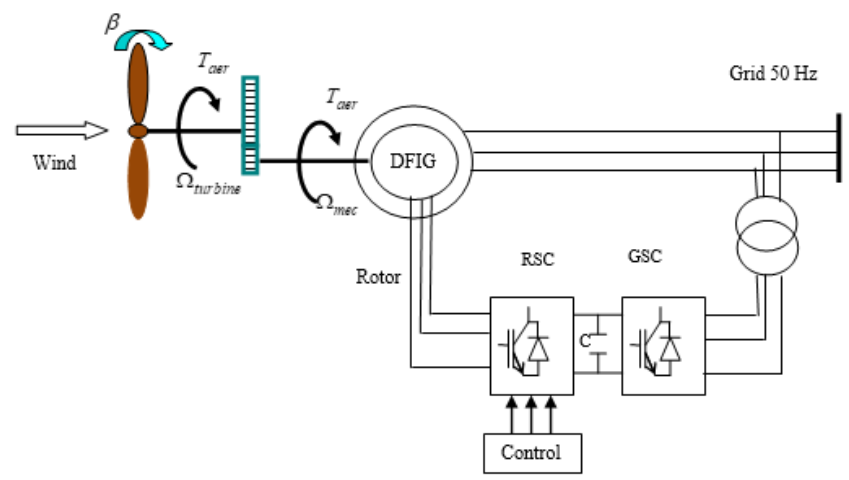

Figure 1. Scheme diagram of DFIG-based wind turbine

\subsection{Turbine modeling}

The expression of the aerodynamic power is presented by the (1) [12]:

$P_{t}=\frac{1}{2} C_{p}(\lambda) \rho \pi R^{2} v^{3}$

The $C_{P}(\lambda)$ is power coefficient, is a nonlinear function of the relative speed ratio $\lambda=\frac{\Omega R}{v}$, with $v$ is wind speed $(\mathrm{m} / \mathrm{s}), \rho$ is the air density $(\mathrm{kg} / \mathrm{m} 3), R$ is the radius of the rotor blades $(\mathrm{m}), \Omega$ is the angular frequency of the blades the mechanical rotation speed and $(\mathrm{rad} / \mathrm{s})$.

The power coefficient of the wind turbine is shown in the Figure 2. This figure indicates that the tip speed ratio is kept equal to $\lambda_{\text {opt. }}$, the $C_{P}(\lambda)$ capture the maximum power [12], [13].

$$
\begin{aligned}
& \left\{\begin{array}{l}
v_{d s}=R_{s} i_{d s}+\frac{d}{d t} \phi_{d s}-\omega_{s} \phi_{q s} \\
v_{q s}=R_{s} i_{q s}+\frac{d}{d t} \phi_{q s}+\omega_{s} \phi_{d s}
\end{array}\right. \\
& \left\{\begin{array}{l}
v_{d r}=R_{r} i_{d r}+\frac{d}{d t} \phi_{d r}-\left(\omega_{s}-\omega\right) \phi_{q r} \\
v_{q r}=R_{r} i_{q r}+\frac{d}{d t} \phi_{q r}+\left(\omega_{s}-\omega\right) \phi_{d r}
\end{array}\right. \\
& \left\{\begin{array}{l}
\phi_{d s}=L_{s} i_{d s}+M i_{d r} \\
\phi_{q s}=L_{s} i_{q s}+M i_{q r}
\end{array}\right. \\
& \left\{\begin{array}{l}
\phi_{d r}=L_{r} i_{d r}+M i_{d s} \\
\phi_{q r}=L_{r} i_{q r}+M i_{q s}
\end{array}\right.
\end{aligned}
$$




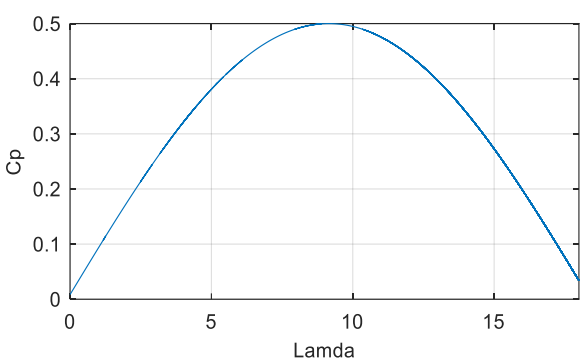

Figure 2. Power coefficient of wind turbine

\subsection{Modeling of the DFIG}

The active and reactive stator and rotor powers are represented as (6), (7) [14]

$$
\begin{array}{r}
\left\{\begin{array}{l}
P_{s}=v_{d s} i_{d s}+v_{q s} i_{q s} \\
Q_{s}=v_{q s} i_{d s}-v_{d s} i_{q s}
\end{array}\right. \\
\left\{\begin{array}{l}
P_{r}=v_{d r} i_{d r}+v_{q r} i_{q r} \\
Q_{r}=v_{q r} i_{d r}-v_{d r} i_{q r}
\end{array}\right.
\end{array}
$$

the electromagnetic torque is given by (8):

$$
T_{e m}=p\left(\varphi_{d s} i_{q s}-\varphi_{q s} i_{d s}\right)
$$

\section{DFIG CONTROL STRATEGY}

\subsection{Vector control of the active and reactive powers}

To independently control the active and reactive stator powers, we use the vector control which makes the DFIG similar to a DC motor

$$
\varphi_{s}=\varphi_{d s} \quad \Rightarrow \quad \varphi_{q s}=0
$$

The torque is simplified as shown below:

$$
\left\{\begin{array}{c}
\varphi_{d s}=L_{s} i_{d s}+M i_{d r} \\
0=L_{s} i_{q s}+M i_{q r}
\end{array}\right.
$$

Neglecting the stator resistance gives the (12)

$$
\left\{\begin{array}{l}
v_{d s}=0 \\
v_{q s}=V_{s}
\end{array}\right.
$$

The equations (12) are obtained when replacing the rotor flux (5) in (3), the rotor voltages are:

$$
\left\{\begin{array}{l}
v_{d r}=\sigma L_{r} \frac{d i_{d r}}{d t}+R_{r} i_{d r}-\sigma L_{r} \omega_{r} i_{q r}+\frac{M}{L_{s}} \frac{d \varphi_{d s}}{d t} \\
v_{q r}=\sigma L_{r} \frac{d i_{q r}}{d t}+R_{r} i_{q r}+\sigma L_{r} \omega_{r} i_{d r}+\frac{M}{L_{s}} \omega_{r} \varphi_{d s}
\end{array}\right.
$$

where: $\omega_{r}=\omega_{s}-\omega=g \omega_{s}$ is the slip frequency, $g$ is the slip range and $\sigma=1-\frac{M^{2}}{L_{s} L_{r}}$ is the leakage coefficient. The rotor voltages can be rewritten as follows (13):

$$
\left\{\begin{array}{l}
v_{d r}=\sigma L_{r} \frac{d i_{d r}}{d t}+R_{r} i_{d r}+f_{e m, d} \\
v_{q r}=\sigma L_{r} \frac{d i_{q r}}{d t}+R_{r} i_{q r}+f_{e m, q}
\end{array}\right.
$$


with $f_{e m, d}$ and $f_{e m, q}$ are the coupling terms (14):

$$
\left\{\begin{array}{c}
f_{e m, d}=-\sigma L_{r} \omega_{r} i_{q r}+\frac{M}{L_{s}} \cdot \frac{d \varphi_{d s}}{d t} \\
f_{e m, q}=-\sigma L_{r} \omega_{r} i_{d r}+\frac{M}{L_{s}} \cdot \omega_{r} \cdot \varphi_{d s}
\end{array}\right.
$$

The stator active and reactive powers are given by the (15):

$$
\left\{\begin{array}{l}
P_{S}=-V_{s} \cdot \frac{M}{L_{s}} i_{r q} \\
Q_{s}=-V_{s} \cdot \frac{M}{L_{s}}\left(i_{r d}-\frac{\varphi_{s}}{M}\right)
\end{array}\right.
$$

The rotor current along the $\mathrm{d}$ and $\mathrm{q}$ axes is represented by (16) and (17)

$$
\begin{aligned}
& i_{r d}=\frac{1}{\sigma L_{r}}\left(v_{d r}-R_{r} i_{r d}+\sigma L_{r} \omega_{r} i_{r q}\right) \\
& i_{r q}=\left(v_{r q}-R_{r} i_{r q}-\sigma L_{r} \omega_{r} i_{r d}-g \frac{M}{L_{s}} v_{s}\right) \frac{1}{\sigma L_{r}}
\end{aligned}
$$

\section{WIND TURBINE CONTROL BASED ON DFIG}

\subsection{SMC control}

Sliding mode control is a mode of operation of variable structure control systems (VSCS). It is robust in view of the insensitivity to parametric variations and to external disturbances.

\subsection{Choice of switching surface}

The sliding surface given by Slotine is defined as (18) [15]:

$$
S(X)=\left(\frac{\partial}{\partial t}+\lambda_{X}\right)^{r-1} e(X)
$$

where: $e(X)$ is the error tracking; $r$ : system order and $\lambda_{\chi}$ is a positive coefficient.

\subsection{Condition of convergence}

The existence of SMC can be proved by using a Lyapunov function (19).

$V(X)=\frac{1}{2} S^{2}(X)$

The derivative is given by (20):

$\dot{V}(X)=S(X) \dot{S}(X)$

To make the Lyapunov function derivative of (19) the negative definite, we have to find adequate control input. To ensure stability, the control is designed as follows (21) [16], [17]

$$
S(X) \dot{S}(X)<0
$$

The sliding mode control algorithm consists of two terms: a discontinuous term which ensures the stability of the system and an equivalent term which brings back the state of the system on the sliding surface [18], [19]:

The control algorithm is defined by (22):

$$
u=u_{e q}+u_{n}
$$

where:

$$
u_{n}=K \operatorname{sign}(S(X))
$$




\section{SUPER-TWISTING SLIDING MODE CONTROL DESIGN}

To remedy the problem of chattering during the implementation of the control sliding mode, we use other more efficient techniques called super-twisting ST algorithm [20], [21].

The control $u_{S T}$ control contains the sum of two terms (24) [22], [23]:

$$
\left\{\begin{array}{l}
u_{S T}=u_{1}+u_{2} \\
\dot{u}_{1}=-\lambda \operatorname{sign}(S) \\
u_{2}=-\alpha|s|^{\frac{1}{2}} \operatorname{sign}(S)
\end{array}\right.
$$

where:

$\alpha>0, \lambda>0$

The convergence condition is given by (25) [24] [25]:

$$
\left\{\begin{array}{l}
\lambda>\frac{C}{K_{m}} \\
\alpha^{2} \geq \frac{4 C K_{M}(\lambda+C)}{K_{m}^{3}(\lambda-C)}
\end{array}\right.
$$

where $C, K_{M}, K_{m}$ are theconstants values of super-twisting sliding mode controller.

Figure 3 show the state trajectory of the $S$ and $\dot{S}$ phase plane.

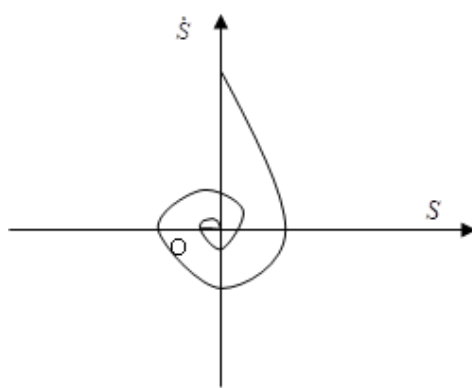

Figure 3. Trajectory phase plane of ST algorithm

\subsection{Super-Twisting sliding mode control design}

The errors of the powers are given by (26):

$$
\left\{\begin{array}{l}
S\left(P_{S}\right)=e_{P S}=P_{S} *-P_{S} \\
S\left(Q_{S}\right)=e_{Q S}=Q_{S}{ }^{*}-Q_{S}
\end{array}\right.
$$

where $P_{S}{ }^{*}$ and $Q_{S}{ }^{*}$ are the reference values of the statoractive and reactive powers.

Then we will have:

$$
\begin{aligned}
& \dot{S}\left(P_{S}\right)=\dot{P}_{S} *-\dot{P}_{S} \\
& \dot{S}\left(Q_{S}\right)=\dot{Q}_{S} *-\dot{Q}_{S}
\end{aligned}
$$

Substituting (15) and (17) into (27) leads to:

$\dot{S}\left(P_{s}\right)=\dot{P}_{s}^{*}+\left(v_{r q}-R_{r} i_{r q}-\sigma L_{r} \omega_{r} i_{r d}-g \frac{M}{L_{s}} V_{s}\right) \frac{1}{\sigma L_{r}}$

When the state of the system is on the surface of sliding, then: 


$$
S\left(P_{S}\right)=0 ; \dot{S}\left(P_{S}\right)=0 ; v_{r q}^{n}=0
$$

so, the equivalent command is given by:

$$
v_{r q}^{e q}=R_{r} i_{r q}+\sigma L_{r} \omega_{r} i_{d r}+g \frac{M V_{s}}{L_{s}}+\ddot{i}_{r q} \cdot \frac{V_{s} M}{L_{s}}
$$

Therefore:

$$
v_{r q}^{n}=-\lambda|S|^{\rho} \operatorname{sign}(S)-\int \alpha \operatorname{sign}(S)
$$

The stator reactive power of the DFIG is represented by substituting (15) and (16) into (28) leads to:

$$
\dot{S}\left(Q_{s}\right)=\dot{Q}_{s}{ }^{*}+V_{s} \frac{M}{L_{s} \sigma L_{r}}\left(v_{r d}-R_{r} i_{r d}+\sigma L_{r} \omega_{r} i_{r q}\right)
$$

when:

$S\left(P_{S}\right)=0 ; \dot{S}\left(P_{S}\right)=0 ; v_{r d}^{n}=0$

The equivalent command is $v^{e q} r$ is defined as:

$$
v_{r d}^{e q}=-\frac{\sigma L_{r}}{M}\left(\lambda \ddot{\varphi}_{s}-\lambda M \ddot{i}_{r d}-\dot{\varphi}_{s}-\frac{M R_{r}}{\sigma L_{r}} i_{r d}+M \omega_{r} i_{r q}\right)
$$

hence:

$$
v^{n} r d=-\lambda|S|^{\rho} \operatorname{sign}(S)-\int \alpha \operatorname{sign}(S)
$$

Figure 4 shown the block diagram of the DFIG controlled by the second order sliding mode which uses the super-twisting algorithm.

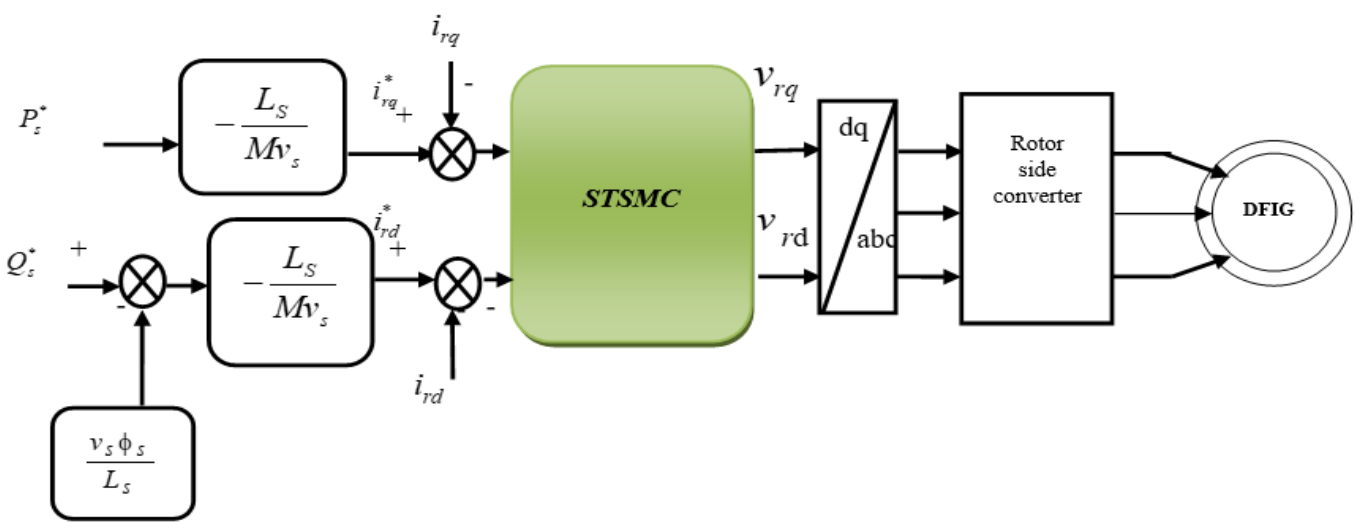

Figure 4. Structure of STSM control

\section{RESULTS AND DISCUSSION}

The block diagram (Figure 4) is validated by a simulation using the parameters indicated in the appendix. A comparison between the two controllers STSMC and classic SMC is applied to a DFIG. This comparison shows that the STSMC is more efficient and robust than SMC. Figure 5 illustrates the reference of the active and reactive power.

Table 1. DFIG parameters nominal

\begin{tabular}{ccc}
\hline $7.5 \mathrm{KW}$ & $400 / 690 \mathrm{~V}$ & $50 \mathrm{~Hz}$ \\
\hline$P=2$ & $R_{S}=0.455 \Omega$ & $R_{r}=0.62 \Omega$ \\
\hline$M=0.078 \mathrm{H}$ & $L_{S}=0.084 \mathrm{H}$ & $L_{r}=0.081 \mathrm{H}$ \\
\hline
\end{tabular}

Table 2. Parameters turbine

\begin{tabular}{c}
\hline Diameter $=14 m$ \\
\hline Gearbox $=28$ \\
\hline Number of blades $=3$
\end{tabular}

Table 3. (DFIG+Turbine)

$\frac{J=50 \mathrm{Kg} \cdot \mathrm{m}^{2}}{f=0.071 \mathrm{~N} \cdot \mathrm{m} \cdot \mathrm{s} / \mathrm{rd}}$




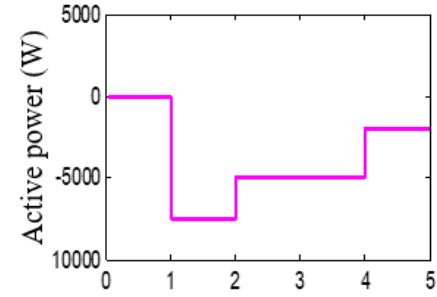

Time $(\mathrm{s})$

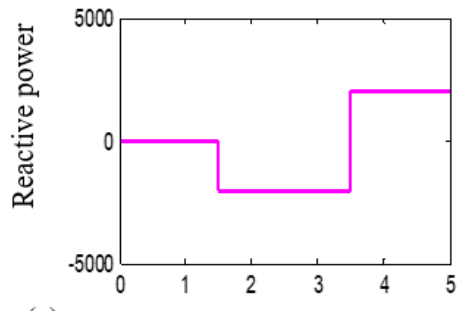

Figure 5. Reference of stator's powers

As clearly shown in Figure 6 and Figure 7, the super-twisting sliding mode control-based system has almost similar tracking performance as the conventional sliding mode control-based system of DFIG stator's powers. It is found that classical sliding mode control-based system suffers from chattering effect; whereas STSMC based system is free from this phenomenon. Figure 8 and Figure 9 illustrate the direct and quadrature rotor current. Figure 10 shows the dynamic responses of the electromagnetic torque. The control by the super-twisting sliding mode of the DFIG gives a good poursuit and is better than SMC controller.
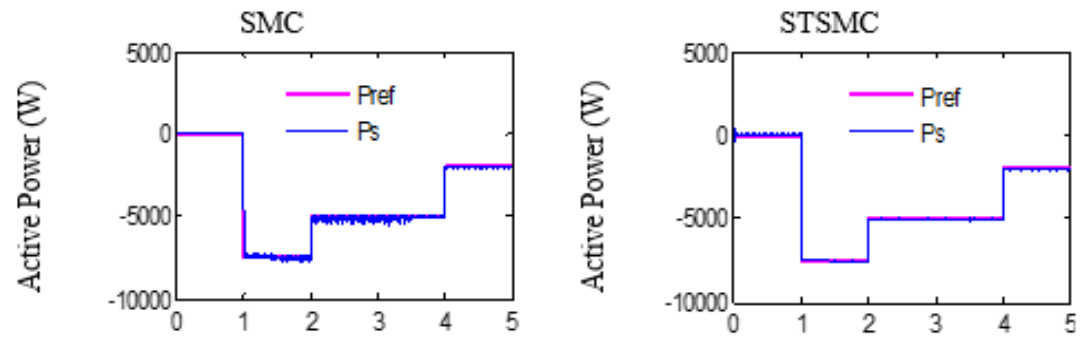

Figure 6. Active power tracking performance
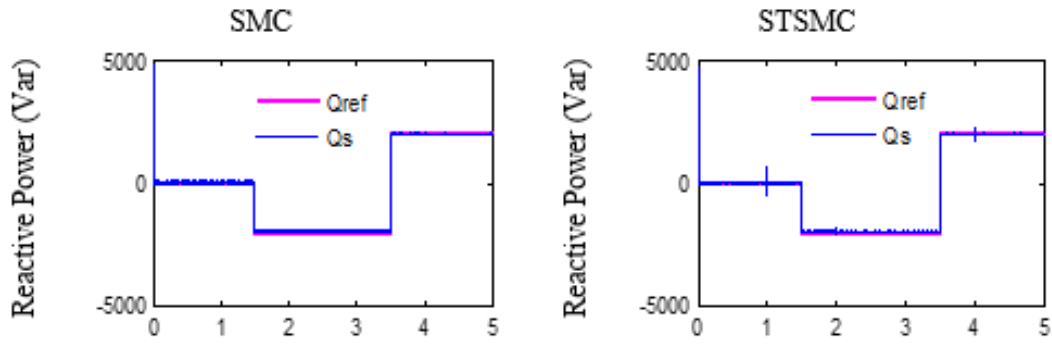

Figure 7. Reactive power tracking performance
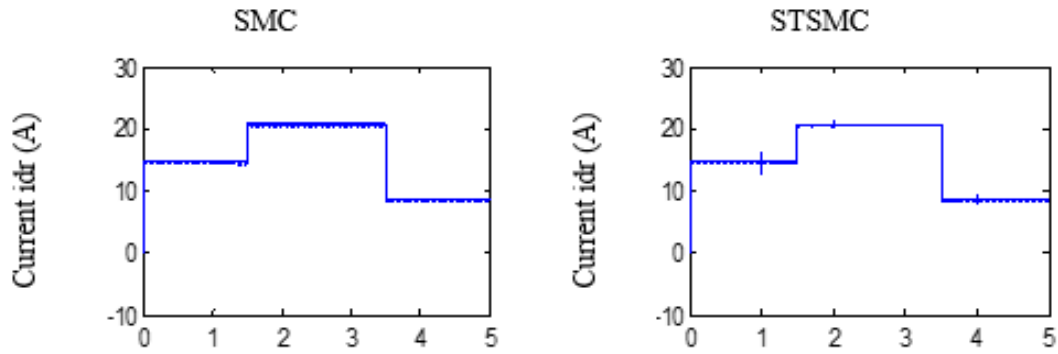

Figure 8. Current idr 

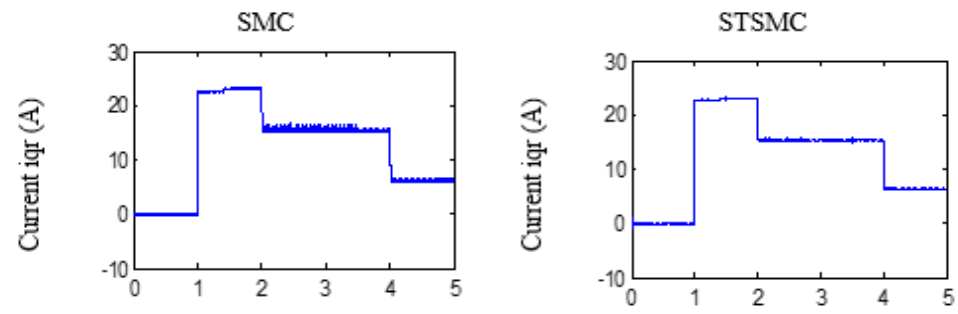

Figure 9. Current iqr
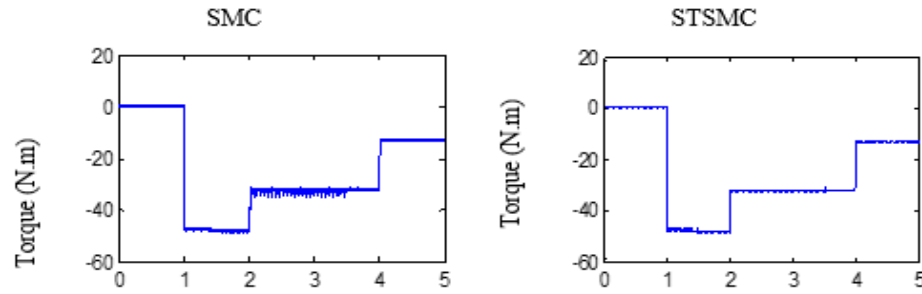

Figure 10. Torque

\section{CONCLUSION}

The application of the STSMC algorithm on a DFIG has been shown in this article. The STSMC algorithm is used for stator's powers control. The proposed approach gives good performance (good tracking, disturbance rejection and minimizes the chattering phenomenon).

\section{REFERENCES}

[1] A. Gupta, S.N. Singhand, D.K. Khatod, "Modeling and simulation of doubly fed induction generator coupled with wind turbine-an overview" Journal of Engineering, Computers \& Applied Sciences (JEC\&AS), vol. 2, no. 8, pp. 45-54, 2013.

[2] F. Poitier, T. Bouaouchiche, M. Machmoum, "Advanced control of a doubly-fed induction generator for wind energy conversion,” Electric Power System Research., vol. 79, no. 7, pp.1085-1096,2009.

[3] G. Pannell, D. Atkinson, B. Zahawi, Analytical Study of Grid-Fault Response of Wind Turbine Doubly Fed Induction Generator," IEEE Transactions on Energy Conversion, vol. 25, no. 4, pp. 1081-1091, 2010.

[4] B. Beltran, M. Benbouzid, T. Ahmed-Ali, H. Mangel, "DFIG-Based Wind Turbine Robust Control Using HighOrder Sliding Modes and a High Gain Observer," International Review on Modelling and Simulations, vol. 4, no. 3, pp. 1148-1155, Nov.2011.

[5] J. A. Moreno and M. Osorio, "Strict Lyapunov functions for the super-twisting algorithm," IEEE Transactions on Automatic Control, vol. 57, no. 4, pp. 1035-1040, 2012.

[6] C. Evangelista, P. Puleston, F. Valenciaga, and L. M. Fridman, "Lyapunov-designed super-twisting sliding mode control for wind energy conversion optimization," IEEE Transactions on Industrial Electronics, vol. 60, no. 2, pp. 538-5545, 2013.

[7] K. Belgacem, A. Mezouar, A. Massoum, "Sliding Mode Control of a Doubly-fed Induction Generator for Wind Energy Conversion," International Journal of Energy Engineering, vol. 3, no. 1, pp. 30-36, 2013.

[8] Utkin, V. I., "Sliding modes and their application in variable structure systems," Mir, Moscou, 1978

[9] S. Benelghali, M.E.H. Benbouzid, T. Ahmed-Ali and J.F. Charpentier, "High-order sliding mode control of a marine current turbine driven doubly-fed induction generator," IEEE J. Ocean. Eng., vol. 35, no. 2, pp. 402-411, Apr. 2010.

[10] B. Beltran, M.E.H. Benbouzid, T. Ahmed-Ali, "Second-Order Sliding Mode Power and Grid Fault-tolerance of a DFIG-based Wind Turbine," Revue of sciences and Technology. vol. 2, no 1, January,2011.

[11] I. Koley, S. Ghosh, A.G. Roy, P.K. Saha, G.Kr. Panda, "Matlab Modeling and Simulation of Grid Connected Wind Power Generation Using Doubly Fed Induction Generator," International Journal of Computational Engineering Research, vol. 4, no. 7, pp. 28-34, July 2014.

[12] B. Hamane, M. L. Doumbia, M. Bouhamida, M. Benghanem, "Control of Wind Turbine Based on DFIG Using Fuzzy-PI and Sliding Mode Controllers," IEEE Proceedings Ninth International Conference on Ecological Vehicles and Renewable Energies (EVER), Monte-Carlo (Monaco), French, pp. 440-448, 2014.

[13] B. Beltran, A. Benbouzid, "A Second-order sliding mode control of a doubly fed induction generator driven wind turbine," IEEE Transactions on Energy Conversion, vol. 27, no. 2, pp. 261-269, 2012. 
[14] K. Belgacem, A. Mezouar, N. Essounbouli, "Design and Analysis of Adaptive Sliding Mode with Exponential Reaching Law Control for Double-Fed Induction Generator Based Wind Turbine," International Journal of Power Electronics and Drive System (IJPEDS), vol. 9, no. 4, pp. 1534 -1544, 2018.

[15] B. Belkacem, "Hybrid Fuzzy Sliding Mode Control of a DFIG Integrated into the Network," International Journal of Power Electronics and Drive System (IJPEDS), vol. 3, no. 4, pp. 351-364, 2013.

[16] Y. Krim, D. Abbes, S. Krim, M. Faouzi Mimouni, "Classical vector, first-order sliding mode and high-order sliding-mode control for a grid-connected variable speed wind energy conversion system: A comparative study," Wind Engineering, vol. 42, no. 1, pp. 16-37, 2018.

[17] Abdeddaim S., Betka, "Optimal tracking and robust power control of the DFIG wind turbine," Electrical Power and Energy Systems (ELSIVER), vol. 49, pp. 234-242, 2013.

[18] H. Majid, H. Abouaïssa, "Comparative Study of a Super-Twisting Sliding Mode Observer and an Extended Kalman Filter for a Freeway Traffic System,” Cybernetics and Information Technologies., vol.15, no 2, pp. 141-158, 2015.

[19] Liu N., Ling R., Huang Q., Zhu Z., "Second-Order Super-Twisting Sliding Mode Control for Finite-Time LeaderFollower Consensus with Uncertain Nonlinear MultiagentSystems," Hindawi Publishing Corporation Mathematical Problems in Engineering., 2015.

[20] A. Boualouch, T. Nasser, A. Essadki, A. Boukhriss, A. Frigui, "A Robust Power Control of a DFIG used in Wind Turbine Conversion System,” International Energy Journal. vol. 17, no. 1, pp. 1-10, 2017.

[21] A. Tamaarat and A. Benakcha, "Performance of Active and Reactive Power Control in a DFIG -based Wind Turbine," Revue des Energies Renouvelables, vol. 20, no. 4, pp. 635 - 647, 2017.

[22] S. Ramtin., M. Seyed., A. Mohammad., M. R. Agha Kashkooli, "Super-Twisting Sliding Mode Direct Power Control of Brushless Doubly Fed Induction Generator," IEEE Transactions on Industrial Electronics, vol. 65, no. 11, pp. 9147-9156, Mar. 2018.

[23] S. Hongchang, H. Yaozhen., Z.Lvyuan, "Maximum Wind Power Tracking of Doubly Fed Wind Turbine System Based on Adaptive Gain Second-Order Sliding Mode" Journal of Control Science and Engineering, 2018.

[24] H. Yaozhen, M. Ronglin., "Adaptive-Gain Second-Order Sliding Mode Direct Power Control for Wind-TurbineDriven DFIG under Balanced and Unbalanced Grid Voltage,” Energies, vol. 12, no. 20, pp. 1-18, 2019.

[25] I. EL Karaoui, M. Maaroufi, "Robust power control methods for wind turbines using DFIG-generator," International Journal of Power Electronics and Drive System (IJPEDS), vol. 10, no. 4, pp. 2101-2117, Dec. 2019.

\section{BIOGRAPHIES OF AUTHORS}
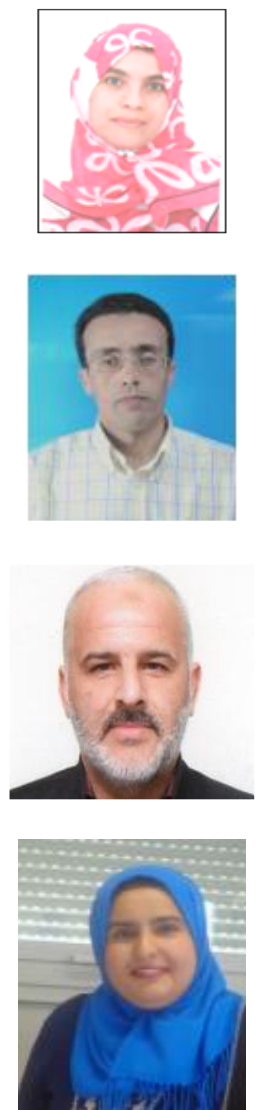

HouariaAbdelli was born in Algeria in 1969. She is Ph.D student in the Department of Electrical Engineering at the University of Sciences and Technology (USTO-MB) of Oran, Algeria. She received Magister degree in Industrial control of electrical drives and diagnosis from the University of Science and Technology of Oran (USTO-MB), Algeria in 2011. Her major research interests are modeling, control of electrical machines and control of wind turbines.

Abdelkader MEZOUAR was born in Mascara, Algeria, in 1974. He received the B.S. and M.S. degrees in Electrical Engineering from National Polytechnic School, Algiers, Algeria, in 1997 and 1999 respectively. Subsequently, he received the Ph.D. degree and the university habilitation from DjillaliLiabes University, Sidi Bel Abbès, Algeria, in 2006 and 2008 respectively. He is currently the president of the Laboratory of Electrical Engineering, Taher Moulay University, Saida, Algeria. His research interests include electrical machines and drives, sliding mode control, observer techniques and renewable energy

Mokhtar Bendjebbar was born on August, 16, 1965 in Relizane Algeria. He received received the B.S degree in electrical engineering and the M.S. and PhD degrees in electrical and control systems from the University of Sciences and Technology of Oran M.B., Algeria, in 1989, 1993, and 2007, respectively. He is currently Professor of Electrical Engineering at the University of Sciences and Technology of Oran. His research interests include Electrical machines and Drives Control, Power Electronics, as well as Intelligent Control and Diagnosis.

Kheira Belgacem was born in Saida Algeria in 1977. Received B.S. degree in Electrical Engineering from Taher Moulay University, Saida, Algeria, in 2001 and the M.S. degree from High National Schools of Technical Studies (ENSET) in 2009. Subsequently, she received the Ph.D. degree from DjillaliLiabes University, Sidi Bel Abbès, Algeria, in 2014. She is currently a member of the Laboratory of Electrical Engineering, Taher Moulay University Saida, Algeria. His research interests include electrical machines and drives, sliding mode control, modelling and control of wind turbines, and renewable energy. 